\title{
UK protects science base, but cuts overall spending
}

London. Britain plans to cut public spending on research and development (R\&D) even further next year, especially at the Department of Trade and Industry and the Department of Defence, according to Whitehall officials speaking after the government announced the annual budget last week.

But Kenneth Clarke, the Chancellor of the Exchequer, said that the government would protect spending on the "science base" - which includes programmes funded through the research councils and universities - from the widespread cuts in public spending, in line with the Conservative party's election promise last year to make science a top priority.

The United Kingdom will increase spending on the research councils and other related institutions in the financial year beginning next April by 4.2 per cent to $£ 1.08$ billion (US\$1.59 billion), just above the anticipated rate of inflation. It also plans to increase spending the following year by a further 3.5 per cent.

The government will also increase the budget for universities by 6.7 per cent. But it has earmarked most of this money to pay for extra students, and it is unclear how much will go to research.

Nevertheless, officials at the Office of Science and Technology(OST) say that total government spending on R\&D will probably continue to fall - it has dropped two per cent in real terms since last year. Official figures are not yet available, because individual departments are still deciding how to divide the lump sums they have been allocated.

William Waldegrave, the science minister will decide later this month how much individual research councils get from the science budget, on advice from the Advisory Board for the Research Councils (ABRC), which meets for the last time on 15 December.

Sir David Phillips, the chairman of the ABRC, describes the outcome of this year's budget negotiations - which were particularly difficult because of the current budget deficit - as "a very good settlement compared to what it could have been".

OST officials say that the coherence of the government's strategy to link science to wealth creation, outlined in the May white paper (policy document), helped them to fend off spending cuts. They had argued that such cuts would sacrifice the initiatives this strategy had generated, and thus threaten Britain's long-term economic prospects.

The pressure group Save British Science said it welcomed the chancellor's decision to protect spending on the science base, but was nonetheless concerned about the drop in total $R \& D$ spending.

\section{Fermat's theorem proves elusive to the last}

London. The proof of Fermat's last theorem, having escaped mathematicians for over three centuries, is still proving more elusive than it appeared six months ago, when Andrew Wiles of Princeton University outlined his solution to a packed meeting at the Newton Institute at

Cambridge University in England.

At the time, mathematicians hailed the presentation as one of the most significant achievements of the century, although they acknowledged that Wiles still needed to polish some details. But they have since become somewhat frustrated by Wiles' apparent reluctance to release details of his proof, giving rise to speculation that he had encountered an unanticipated problem.

Last Friday, after several months of growing pressure, Wiles issued a statement confirming their suspicions. The statement said that he has not yet been able to complete a key step in the proof, and that the manuscript remains unsuitable for release, since "a lot of work remains to be done".

Wiles also promised to give a full account of the work that he has carried out on the proof when he presents a scheduled lecture course at Princeton in February.

Few mathematicians who heard Wiles' presentation at Cambridge doubt that he has found the right path to a solution. John Coates, for example, professor of mathematics at Cambridge, who helped set up the meeting, says he is confident that it will still work. But he admits that, as things now stand, the proof remains incomplete.

Fermat's last theorem states that there are no values of $n$ higher than two for which the formula $a^{n}+b^{n}=c^{n}$ can be solved in nonzero integers. The French mathematician claimed he had a proof, but that he could not write it down because the margin of the book he was reading was too narrow; modern mathematicians doubt that his proof was valid, and acknowledge a watertight one will be extremely complex.

Wiles has spent seven years developing an approach that uses a range of recent mathematical advances. His presentation at Cambridge needed three seminars, and its written version is said to run to one-thousand pages in draft form.

But Wiles has only shown his preliminary manuscript to a small circle of mathematicians, who are helping him iron out the final details. This itself has raised eyebrows among some who felt that any problems might be worked out faster if Wiles circulated his manuscript more widely.

Until last Friday, Wiles and his Princeton colleagues had been staying silent about the cause of the delay, and had ignored letters and faxes from other mathematicians who have offered to help. confirms widespread speculation that he has encountered a problem. Much of his proof consists of extending the work of Mateus Flach, like Wiles a doctoral student at Cambridge who now teaches at the University of Heidelberg in Germany, through a number of complex steps. It now appears that his original arguments justifying one of these steps are insufficient.

"In his Cambridge presentation, Wiles seemed to have found a short-cut, but it appears that this has not worked out," says one mathematician. "As a result, the proof of this particular link may have to be established by more conventional means."

Mathematicians are confident that such efforts will eventually succeed. "No-one has faulted his line of reasoning, or really believes that the link he makes is not valid," says Ken Ribet, professor of mathematics at the University of California at Berkeley who in the 1980s developed some of the techniques that Wiles uses in his proof.

In his statement, Wiles says that a number of problems which emerged during the review process have been resolved. And a key step in the proof, namely that if the socalled Selmer group is small, then every semi-stable elliptic curve over the rational numbers is modular, has been confirmed.

But the complete proof requires the demonstration of a precise upper bound to the number of elements of the particular Selmer group. This Wiles has not yet achieved, although he remains optimistic of doing so. "I believe that I will be able to finish this in the near future, using the ideas explained in my Cambridge lecture," he says.

Nevertheless, mathematicians are remaining cautious about claiming that the theorem has been proved until this work is completed and Wiles publishes his final manuscript. And many are now quoting the words of the Dutch poet Piet Heim: "Problems worthy of attack, prove their worth by hitting back."

David Dickson 